\title{
A Dynamic Model of Risk Propagation Mechanism Analysis in Metro Construction
}

\author{
Chao Dong ${ }^{1,2}$ \\ ${ }^{1}$ School of Civil Engineering \&Mechanics, Huazhong University of Science \& Technology, Wuhan \\ (430074), China \\ ${ }^{2}$ Hubei Engineering Research Center for Virtual, Safe and Automated Construction (ViSAC), HUST, \\ China
}

\section{memorize.cool@163.com}

Keywords: metro construction; multi-level network; risk propagation; multi-level risk network. Abstract. Safety risks are complicated in the metro construction, so the identification and control of the risk factors as well as the mitigation of coupling effect of risk events are the important ways to improve the safety performance of the deep foundation pit construction project. The purpose of this paper is to identify the risk sources, figure out the risk propagation path towards accident by establishing the relationships between risk factors and safety incidents (accidents and near-miss incidents). Firstly, a new concept of multi-level risk network based on accident is proposed to describe the complexity of risk relationships in the deep foundation pit construction. Then the critical variables and risk propagation paths are identified with the help of the proposed model, appropriate suggestions are given to similar projects.

\section{Introduction}

Metro construction projects are, by nature, exposed to multiple accident risks in practice [1]. In the past 10 years, metro construction has presented the powerful momentum for rapid development of urban environments all over the world [2]. Owing to various risk factors under uncertain interrelationship in complex environments, safety violations occur frequently in metro construction [3]. For example, one of the most serious accidents was the foundation pit collapse accident called “2008.11.15” happened in Hangzhou, on November 15, 2008, which killed 21 people [4].

Due to the great impact of metro construction accidents, researchers have paid much attention to analyzing risk factors. Generally, researches on construction risk analysis can be categorized into two groups: one is through learning from accidents [5,6]. Kines et al. [7] analyzed the risk factors for injuries of construction workers' falls from roofs. Ling et al. [8] conducted in-depth case investigation of proximal causes of 40 fatalities from 2006 to 2008 in Singapore construction industry. Cheng et al. [9] studied the cause-effect relationships of occupational accidents in Taiwan construction industry. Hinze et al. [10] studied the causes of 659 visibility-related construction fatalities in the US. Zhou et al. [5] focused their insight into the causes of metro construction accidents.

The other type is expert judgement-based analysis [11-13], which is always conducted through collecting experts' opinions by questionnaires. Yu et al. [11] adopted factor analysis to identify the key factors influencing the metro construction safety. Zhang et al. [14-16] adopted Bayesian network to conduct the cause-effect of metro construction risk analysis based on expert judgement. Liu et al. [13] integrated exploratory factor analysis and structural equation model to examine the risk factors for metro construction during the mechanical tunnel excavation.

Both the accident data-based and questionnaire-based construction safety risk researches provided a good reference to the metro construction projects. However, these studies are too general to the practical projects. As stated by Cárdenas et al. [17], the variables can be classified into causes, conditions and inhibitors. The risk factors in each category cannot be treated equally, as the safety management strategies for dealing with these factors differ. What indeed need in the real construction 
projects is to refer to the experiences of similar projects, especially those accidents happened with similar conditions. Therefore, this study focuses on developing a multi-level risk network for Hangzhou Subway construction collapse (HZSCC) discriminating properties of variables. The development of MLRN will be given in section 2. Section 3 provides the results and discussion, and conclusions are given in section 4 .

\section{Development of MLRN}

Concept of MLRN. In the last decade, complex network has shown its advantages in modeling complex problems [18]. It also has been adopted to describe the time series topologies of near-misses in construction site [19], modeling the event chains of subway construction accidents [5]. However, modeling the risk factors and risk events (i.e. accidents) in a single network lead to neglect of the properties of risk factors as well as the risk propagation mechanism. An example inhibitor variable in the model is "no reaction to the cracks on the road". If the cracks on the road occurs, the reaction determines whether the event result in the collapse of the road, and the cascade failure of the foundation pit. Besides, the conditions are the conditioning variables, which cannot be controlled by human however, the causes and the inhibitors are the variables that can be controlled by human. Thus, we proposed a multi-level risk network (MLRN) that consists of any sub-networks, which is used to analyze the relationships between the risk factors and accident in the Hangzhou subway construction collapse (HZSCC). The accident related variables are modeled as nodes, and the causal relationships among them are modeled as edges.

Description about the accident. On Nov. 15, 2008, a 75m-long section of the central west underground diaphragm wall collapsed. As a large amount of silt poured into the pit, Fengqing Avenue subsequently collapsed with a maximum depth of about $6.5 \mathrm{~m}$. The accident caused 21 deaths and 24 injuries.

Establishment of MLRN. According to the accident investigation report, we firstly extracted out the variables that are directly related to the accident. To investigate the roles of variables with different properties in the risk propagation path, we grouped them into risk factors (consist of conditions, causes, and inhibitors) and accidents. In this paper, risk factors are defined as those deviations from the requirements of a deep foundation pit construction project (assumptions, expectations, specifications, tolerances, and thresholds), which could lead to risks or exacerbate their impact [20]. Among the risk factors, conditions are the risk factors that are necessary to produce the failure but depend on the causes in the risk network; causes are the risk factors which can lead to failure occurring; inhibitors are the risk factors with the capability of reducing the chance of failure, however, in the risk propagation path into accidents, they always have been failed. Accidents are those conditions or events would directly lead to losses. The variables extracted from the accident investigation report are listed in Table 1.

As nodes and edges are the basic elements of complex networks, we define the variables (risk factors and accidents) are the nodes, the causal relationships among them are the edges, with arrows directed from the cause to the effect. Furthermore, the accidents are modeled as the first level network, and the risk factors are modeled as the second level network. With the help of Pajek, the directed MLRN for HZSCC has been built containing two levels of sub networks, which was shown in Fig. 1. 
Table 1. Variables directly related to HZSCC accident

Risk factors

\begin{tabular}{|c|c|c|c|c|c|c|c|}
\hline & \\
\hline \multicolumn{2}{|r|}{ Conditions } & \multicolumn{2}{|r|}{ Causes } & \multicolumn{2}{|c|}{ Failed inhibitors } & & \\
\hline No. & Description & $\mathrm{Nc}$ & Description & No. & Description & No. & Description \\
\hline 1 & $\begin{array}{l}\text { Copious } \\
\text { ground } \\
\text { water }\end{array}$ & 1 & $\begin{array}{l}\text { Unreasonable design } \\
\text { parameters for } \\
\text { foundation pit } \\
\text { retaining structure }\end{array}$ & 1 & $\begin{array}{l}\text { Insufficient } \\
\text { escapeway }\end{array}$ & 1 & $\begin{array}{l}\text { Excessive } \\
\text { deformation of } \\
\text { underground } \\
\text { diaphragm wall }\end{array}$ \\
\hline 2 & $\begin{array}{l}\text { Complex } \\
\text { pipelines }\end{array}$ & 2 & $\begin{array}{l}\text { Deficient design for } \\
\text { the load capacity } \\
\text { around the } \\
\text { foundation pit }\end{array}$ & 2 & $\begin{array}{l}\text { No reaction to } \\
\text { the cracks on the } \\
\text { west protective } \\
\text { wall }\end{array}$ & 2 & $\begin{array}{l}\text { Destruction of } \\
\text { steel support } \\
\text { system }\end{array}$ \\
\hline 3 & $\begin{array}{l}\text { A river or } \\
\text { the east o } \\
\text { the } \\
\text { construction } \\
\text { site }\end{array}$ & 3 & $\begin{array}{l}\text { Late casting of } \\
\text { cushion }\end{array}$ & 3 & $\begin{array}{l}\text { No reaction to } \\
\text { the cracks on the } \\
\text { road }\end{array}$ & 3 & $\begin{array}{l}\text { Instability of } \\
\text { foundation pit }\end{array}$ \\
\hline \multirow[t]{9}{*}{4} & $\begin{array}{l}\text { Continuous } \\
\text { rain }\end{array}$ & 4 & $\begin{array}{l}\text { Late installation of } \\
\text { support }\end{array}$ & & & 4 & $\begin{array}{l}\text { Destroy of the } \\
\text { west diaphragm } \\
\text { wall }\end{array}$ \\
\hline & & 5 & Over excavation & & & 5 & $\begin{array}{l}\text { Collapse of } \\
\text { foundation pit }\end{array}$ \\
\hline & & 6 & Insufficient monitoring & & & 6 & $\begin{array}{l}\text { Rupture } \\
\text { pipelines }\end{array}$ \\
\hline & & 7 & Invalid monitoring & & & 7 & $\begin{array}{l}\text { Water flush into } \\
\text { the foundation pit }\end{array}$ \\
\hline & & 8 & $\begin{array}{l}\text { Deficient design for the } \\
\text { installation } \\
\text { requirement of steel } \\
\text { braces }\end{array}$ & & & 8 & Collapse of road \\
\hline & & 9 & $\begin{array}{l}\text { Incorrect installation of } \\
\text { steel braces }\end{array}$ & & & 9 & $\begin{array}{l}\text { Water flush into } \\
\text { the road }\end{array}$ \\
\hline & & 10 & $\begin{array}{l}\text { Large volumes of } \\
\text { traffic on road }\end{array}$ & & & 10 & $\begin{array}{l}\text { Deaths } \\
\text { injuries }\end{array}$ \\
\hline & & 11 & $\begin{array}{l}\text { Deficient } \\
\text { reconnaissance }\end{array}$ & & & 11 & $\begin{array}{l}\text { Settlement of road } \\
\text { surface }\end{array}$ \\
\hline & & 12 & $\begin{array}{l}\text { Excessive liquidity of } \\
\text { soil }\end{array}$ & & & & \\
\hline
\end{tabular}


13 Remove

the

measures for the soil

below the pit

14 Deficient design for the

safety capacity of

containment structure

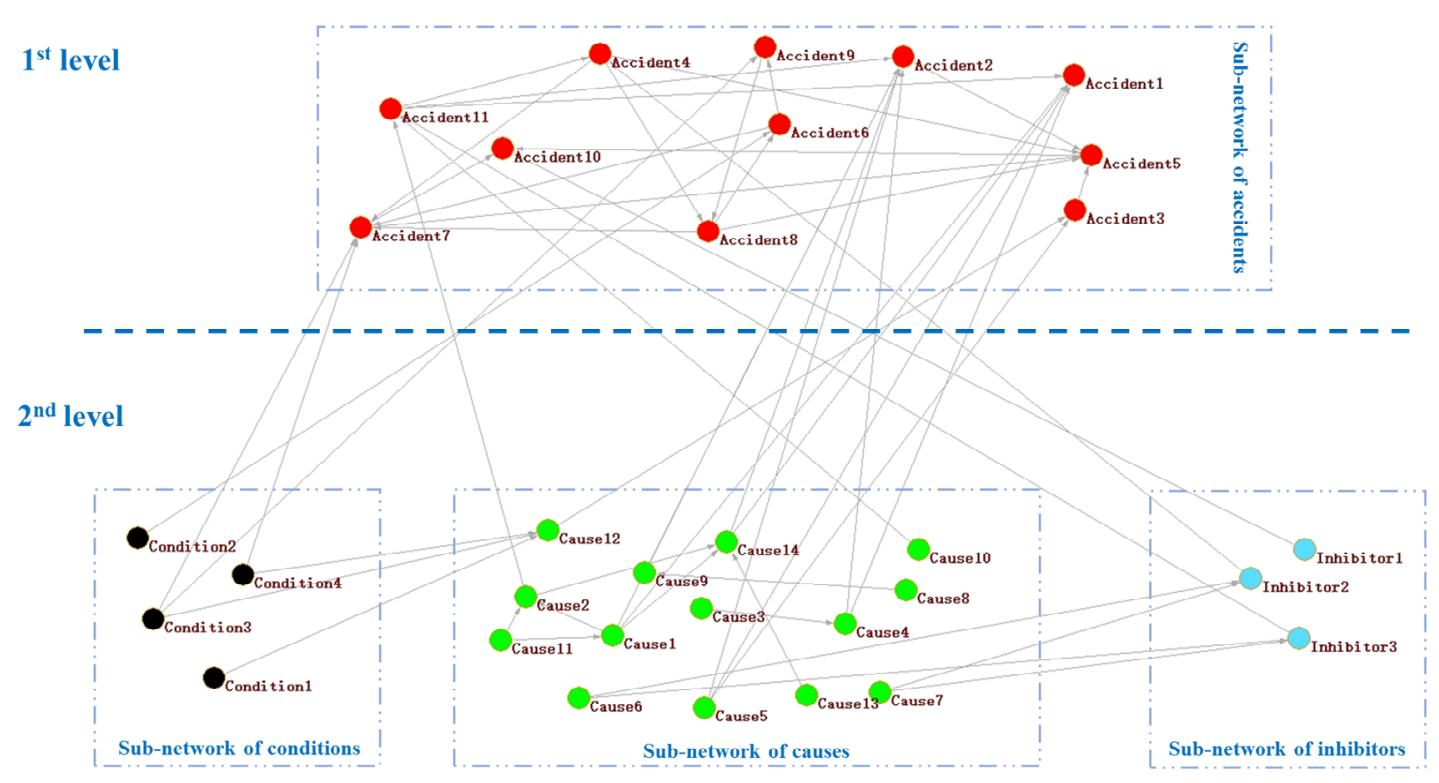

Fig. 1. The structure of MLRN of HZSCC

\section{Results and discussions}

Complex network provides the researchers with a precise visual inspection about the complex relationships among the variables. As shown in Fig. 1, how the risk propagated from the conditions to the accidents has been visualized directly. In this section, we analyze the accident from two points, critical variables and critical risk propagation paths.

Critical variable analysis. Degree is an important topological parameter of complex network in investigating the importance of nodes [21]. As the variables of each sub-network take different roles in the risk propagation of HZSCC accident, it is necessary to identify the critical variables in each sub-network. We calculated the degrees of nodes in each sub-network with Pajek. In the directed MLRN, in-degree indicates the number of causes which would lead to the node, the higher the higher frequency it would happen during the metro construction. The out-degree indicates the number of effects the node would cause. Out-degree is a good indicator for cutting down the risk propagation path, as variables with higher out-degree being deleted with appropriate construction safety management measures, the paths that the nodes directing to would also be removed.

Analysis of conditions. The in-degree for all variables are 0 , because they are the environmental conditions, the happening of which was not caused by human errors. Condition 3 (a river on the east of the construction site) shows a high importance in both the out-degree and the all-degree, which indicates the projects with similar locations (near river etc.) should pay attention to the reinforcement of the river bank to protect the water flush into the construction site. 
Analysis of causes. The relationships among the causes are more complex than conditions. Some of the causes will lead to others, for example, the cause 1 (unreasonable design parameters for foundation pit retaining structure) will lead to the happening of cause 2 (deficient design for the load capacity around the foundation pit), cause 9 (incorrect installation of steel braces) and cause 14 (deficient design for the safety capacity of containment structure), indicating it is an important source for other causes. Cause 1 and cause 14 show high all-degree, showing both of them play important roles in the risk propagation path.
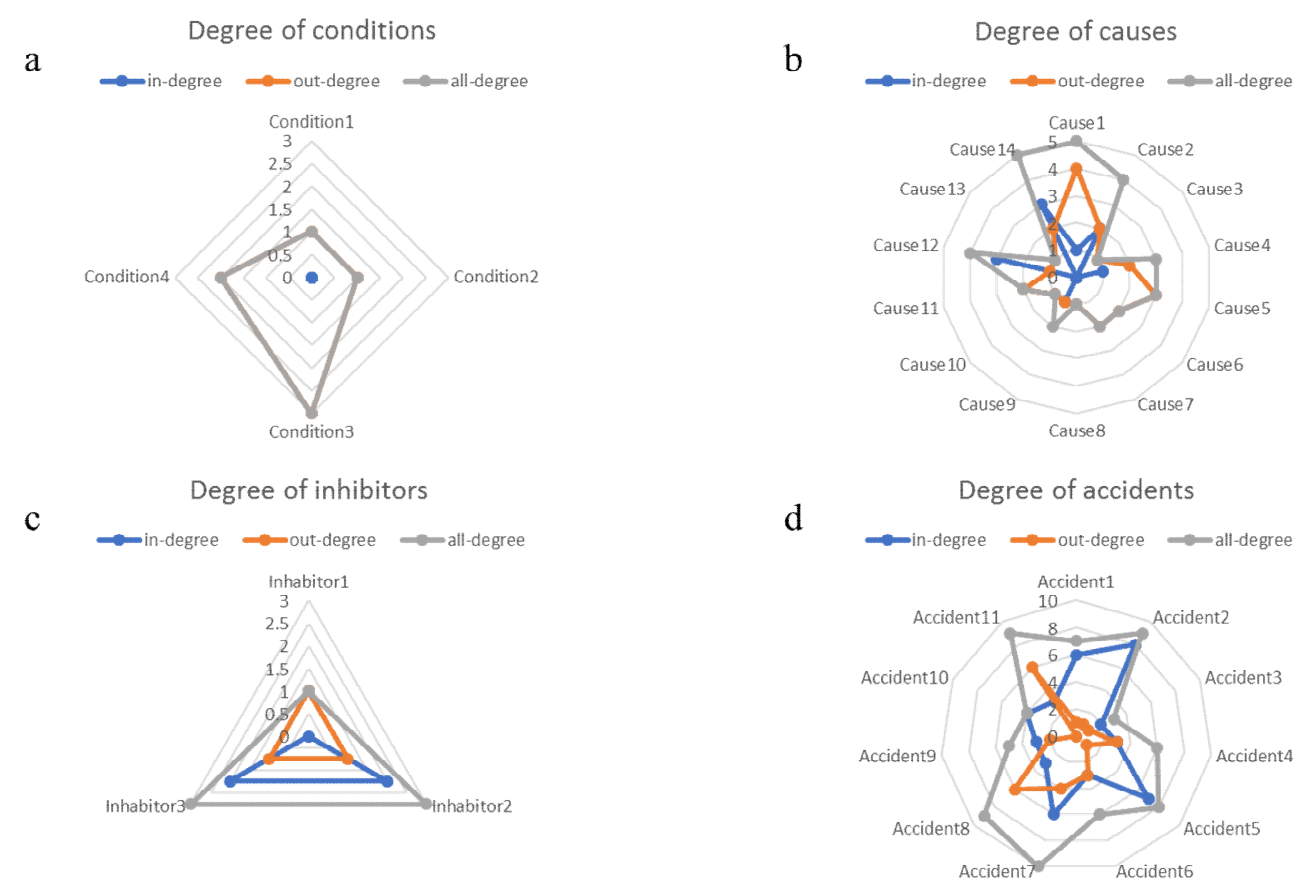

Fig. 2. Degree of sub-networks. (a) degree distribution of conditions; (b) degree distribution of causes; (c) degree distribution of inhibitors; (d) degree distribution of accidents

Analysis of inhibitors. Inhibitor 1 (insufficient escapeway) directly linked to the deaths and injuries of people, showing escapeway has a great importance in decrease losses when accidents happen. Inhibitor 2 and inhibitor 3 are caused by the failure of monitoring systems, suggesting monitoring plays an important role in discovering risks in time and provides the opportunity for the safety managers taking appropriate measures for remedy.

Analysis of accidents. In the HZSCC, the most serious accident (deaths and injuries) is caused by a series of sub-accidents. Accident 2 (destruction of steel support system) has the highest in-degree, showing this variable is related to many other variables, which are cause 3 (late casting of cushion), cause 4 (late installation of support), cause 5 (over excavation), and cause 9 (incorrect installation of steel braces) in this case. All the four causes are closely related to the construction management, uncovering the fact that in the high-speed development of metro construction, it is a huge hidden danger to compress construction period with the sacrifice of safety and quality. Accident 11 (settlement of the road surface) has a very high out-degree, indicating it is an important precursor for other serious accidents, such as collapse of the road, etc. Therefore, the monitoring the settlement is of great importance for the metro construction safety.

Critical risk propagation path. As conditions cannot be controlled but are necessary to accidents when coupled with causes. Thus, investigating the risk propagation path from the condition variables to accidents will give guidance to the projects which have similar conditions with Hangzhou metro line 1 . We defined the risk propagation path (from conditions sub-network to accidents 
sub-network) has the shortest length (containing least number of nodes) as the critical path. The critical path from condition 1 is: copious ground water $\longrightarrow$ excessive liquidity of soil $\longrightarrow$ instability of foundation pit. It suggests the metro construction projects in cities like Wuhan, with abundant underground water should pay attention to take measures in keeping the ground water level under a safe threshold. The direct path (complex pipelines $\rightarrow$ rupture of pipelines) reminding the metro construction project should obtain full knowledge about the underground pipelines near the construction projects, proper migration and monitoring measures should be taken for those having great effect on the construction safety. There are two critical paths originated from condition 3 , which are condition 3 to accident 7 , and condition 3 to accident 9. This suggests the projects near the rivers should pay high attention to the reinforcement of embankment. When extreme weather occurs during the metro construction, proper precipitation measures should be taken.

\section{Conclusion and limitation}

This study has concentrated on the development of multi-level risk network for metro construction, based on the Hangzhou subway construction collapse accident. The properties of accident related variables have been discriminated by four sub-networks, the critical variables for each sub-network have been identified, based on which suggestions have been made for similar projects. The critical risk propagation paths have also been identified, appropriate measures should be taken for the projects with similar condition variables. However, the limitations of this research should be acknowledged, a first limitation concerns the incompleteness of the developed MLRN, as it is based on one accidents case, it remains inherently incomplete because it is unlikely to fully encompass the range of possible risk factors related to metro construction accidents. Another limitation is that we didn't consider the weights for edges in this work, the uncertainties of risk propagation should be considered in the future work.

\section{Acknowledgements}

This research is supported by National Natural Science Foundation of China (No.51678265, $71732001)$.

\section{References}

[1] D. Lieyun, X. Jie, A review of metro construction in China: Organization, market, cost, safety and schedule, Frontiers of Engineering Management 4 (1) (2017) 4-19. DOI: 10.15302/J-FEM-2017015.

[2] Q. Qian, P. Lin, Safety risk management of underground engineering in China: Progress, challenges and strategies, Journal of Rock Mechanics and Geotechnical Engineering 8 (4) (2016) 423-442. DOI: 10.1016/j.jrmge.2016.04.001.

[3] L. Zhang, X. Wu, M.J. Skibniewski, J. Zhong, Y. Lu, Bayesian-network-based safety risk analysis in construction projects, Reliability Engineering \& System Safety 131 (2014) 29-39. DOI: 10.1016/j.ress.2014.06.006.

[4] AFP (2008), 21 dead in China subway accident: state media, https://www.emirates247.com/eb247/news/asia/21-dead-in-china-subway-accident-state-me dia-2008-11-19-1.227244, last access date <17/03/2018>

[5] Z. Zhou, J. Irizarry, Q. Li, Using network theory to explore the complexity of subway construction accident network (SCAN) for promoting safety management, Safety Science 64 (2014) 127-136. DOI: 10.1016/j.ssci.2013.11.029.

[6] X. Zhang, Y. Deng, Q. Li, M. Skitmore, Z. Zhou, An incident database for improving metro safety: The case of shanghai, Safety Science 84 (2016) 88-96. DOI: 10.1016/j.ssci.2015.11.023. 
[7] P. Kines, Construction workers' falls through roofs:: Fatal versus serious injuries, Journal of safety research 33 (2) (2002) 195-208. DOI: 10.1016/S0022-4375(02)00019-1.

[8] F.Y.Y. Ling, M. Liu, Y.C. Woo, Construction fatalities in Singapore, International Journal of project management 27 (7) (2009) 717-726. DOI: 10.1016/j.ijproman.2008.11.002.

[9] C.-W. Cheng, S.-S. Leu, C.-C. Lin, C. Fan, Characteristic analysis of occupational accidents at small construction enterprises, Safety Science 48 (6) (2010) 698-707. DOI: 10.1016/j.ssci.2010.02.001.

[10] J.W. Hinze, J. Teizer, Visibility-related fatalities related to construction equipment, Safety Science 49 (5) (2011) 709-718. DOI: 10.1016/j.ssci.2011.01.007.

[11] Q.Z. Yu, L.Y. Ding, C. Zhou, H.B. Luo, Analysis of factors influencing safety management for metro construction in China, Accident Analysis \& Prevention 68 (2014) 131-138. DOI: 10.1016/j.aap.2013.07.016.

[12] L. Zhang, M.J. Skibniewski, X. Wu, Y. Chen, Q. Deng, A probabilistic approach for safety risk analysis in metro construction, Safety Science 63 (2014) 8-17. DOI: 10.1016/j.ssci.2013.10.016.

[13] W. Liu, T. Zhao, W. Zhou, J. Tang, Safety risk factors of metro tunnel construction in China: An integrated study with EFA and SEM, Safety Science 105 (2018) 98-113. DOI: 10.1016/j.ssci.2018.01.009.

[14] L. Zhang, X. Wu, Y. Qin, M.J. Skibniewski, W. Liu, Towards a Fuzzy Bayesian Network Based Approach for Safety Risk Analysis of Tunnel-Induced Pipeline Damage, Risk Anal 36 (2) (2016) 278-301. DOI: 10.1111/risa.12448.

[15] L. Zhang, X. Wu, H. Liu, Strategies to Reduce Ground Settlement from Shallow Tunnel Excavation: A Case Study in China, Journal of Construction Engineering and Management 142 (5) (2016). DOI: 10.1061/(asce)co.1943-7862.0001087.

[16] L. Zhang, Y. Huang, X. Wu, M.J. Skibniewski, Risk-based estimate for operational safety in complex projects under uncertainty, Applied Soft Computing 54 (2017) 108-120. DOI: 10.1016/j.asoc.2017.01.020.

[17] I.C. Cárdenas, S.S. Al-jibouri, J.I. Halman, F.A. van Tol, Capturing and integrating knowledge for managing risks in tunnel works, Risk Analysis 33 (1) (2013) 92-108. DOI: 10.1111/j.1539-6924.2012.01829.x.

[18] E. Ravasz, A.L. Barabasi, Hierarchical organization in complex networks, Phys Rev E Stat Nonlin Soft Matter Phys 67 (2 Pt 2) (2003) 026112. DOI: 10.1103/PhysRevE.67.026112.

[19] C. Zhou, L. Ding, M.J. Skibniewski, H. Luo, S. Jiang, Characterizing time series of near-miss accidents in metro construction via complex network theory, Safety Science 98 (2017) 145-158. DOI: 10.1016/j.ssci.2017.06.012.

[20] I.C. Cardenas, S.S. Al-Jibouri, J.I. Halman, W. van de Linde, F. Kaalberg, Using prior risk-related knowledge to support risk management decisions: lessons learnt from a tunneling project, Risk Anal 34 (10) (2014) 1923-1943. DOI: 10.1111/risa.12213.

[21] R. Albert, A.-L. Barabási, Statistical mechanics of complex networks, Reviews of modern physics 74 (1) (2002) 47. DOI: 10.1103/RevModPhys.74.47. 